\title{
ORIENTAÇÃO SOBRE SAÚDE BUCAL EM UM CENTRO DE SAƯDE *
}

\author{
Roberto Augusto Castellanos **
}

\begin{tabular}{l} 
RSPU-B/356 \\
\hline
\end{tabular}

Castellanos, R. A. Orientação sobre saúde bucal em um Centro de Saúde. Rev. Saúde públ., S. Paulo, 11:248-57, 1977.

RESUMO: Foi realizado estudo com o fim de verificar qual a orientação sobre saude bucal dada aos clientes que pela primeira vez compareceram a um centro de saúde. Durante o periodo de 2 semanas foram observados 25 clientes; o método utilizado foi o da "observaçäo participante". Os dados necessários para o "diagnóstico educativo" foram colhidos com o auxilio de uma ficha. Da análise destes dados concluitu-se não haver uma adequada orientação com relação $\grave{a}$ saúde bucal, por parte do pessoal responsável. Sugere-se como "tratamento educativo" revisão das normas em relaçâo à saúde da boca e desenvolvimento de um programa educativo, incidental e planejado, integrado às diferentes atividades realizadas pelo Centro. Propóe-se um conteúdo programático responsabilizando o dentista pelo adestramento do pessoal, execufáo e avaliação do programa. Ressalta-se a importância do centro de saúde para o desenvolvimento de programas integrados, preventivos, curativos e educativos. Saúde.

UNITERmos: Saúde bucal. Edacação sanitäria odontológica. Centro de

\section{I NTRODUCAO}

A prevalência mundial das odontopatias, especialmente a cárie dental e a doença periodontal, justificam a organização de programas eficazes de educação em saúde da boca. Contudo, saúde bucal como saúde em geral são termos que têm diferentes significados para diferentes individuos.

Educação em saúde tem sido definida como a "transferência daquilo que se sabe sobre saúde a padrōes desejáveis de comportamento, individual e de grupo, através do processo educativo" ".
Young, citando um comitê de peritos em saúde bucal, expressa que, em uma forma ampla, educação em saúde inclui "todas as experiências que influenciam crenças, atitudes e comportamento de um indivíduo, grupo ou comunidade, com relação à saúde, bem como os processos e esforços para produzir mudanças quando necessário para uma ótima saúde" e, em uma forma mais restrita, "se refere usualmente aos esforços planejados ou formais para estimular experiências que levam ao desenvolvimento de

* Trabalho realizado como requisito da Disciplina Educação em Saúde Pública IV (Problemas em Saúde Pública) do Curso para Mestrado da Faculdade de Saúde Pública da Universidade de São Paulo; apresentado à IX Conferência Internacional de Saúde, celebrada em Otawa, Canadá, de 29 de agosto a 3 de setembro de 1976.

* Do Departamento de Prática de Saúde Pública da Faculdade de Saúde Pública da USP - Av. Dr. Arnaldo, 715 - Săo Paulo, SP - Brasil. 
conhecimentos, atitudes e comportamento que sejam os mais condizentes para alcançar a saúde do individuo, do grupo ou da comunidade" -

Com relação à educação em saúde da boca, entendida como a "totalidade das experiências a que uma pessoa, grupo ou comunidade pode ser exposta e que influenciam favoravelmente práticas, atitudes e conhecimento relativos à saude bucal" ", muitos esforços foram devotados no passado para informar o público; contudo, isso não tem bastado para modificar o comportamento individual e coletivo na medida que se esperava, e inclusive nos paises em que os serviços de assistência dentária são dispensados gratuitamente, as pessoas não se fazem tratar como deveriam. Também está comprovado que a etiologia e tratamento das doenças, bem como a conservação e melhoria da saúde, depende muito mais do comportamento individual e coletivo do que das condições do meio ${ }^{4}$. Tudo indica que é urgente dar uma orientação mais eficaz à educação no que se refere à saúde bucal.

Levando em consideração esses aspectos, uma instituição de saúde, no nosso caso um centro de saude, deve integrar ao seu programa assistencial as atividades preventivas e educativas que possibilitem alcançar seu objetivo principal, ou seja, a saude de seus clientes ${ }^{5}$

Tendo em mente este objetivo e o fato de ter recebido informação verbal de que alguns pacientes da seção de higiene dentária de um centro de saúde da cidade de São Paulo faltavam com treqüência às consultas marcadas com antecedência ocasionando atraso na conclusão de seu tratamento e prejuizo para outras que deixavam de ser atendidas - pensou-se em observar, em todos os serviços, qual o tipo de orientação, com relação à saúde bucal, estavam recebendo os clientes que compareciam pela primeira vez ao centro de saúde. Numerosas causas podem ser consideradas quanto ao não comparecimento de pacientes às consultas marcadas; portanto, a adequada ou inadequada orientação que ele recebe sobre aspectos de saúde bucal só deverá ser um fator de relativa influência. Dado o curto periodo de estágio em cada um dos diversos serviços, as conclusões que deste estudo possam ser tiradas têm limitaçōes; entretanto, como hipóteses de trabalho, consideramos poderem ser válidas.

Portanto, o objetivo deste trabalho foi observar o tipo de orientação sobre saúde bucal que é recebida pelos clientes que compareceram pela primeira vez ao centro de saúde selecionado da cidade de São Paulo, através de todos os seus contatos com os diferentes serviços.

\section{MATERIAL E METODOS}

\subsection{População:}

Dadas as limitações de tempo, não foi possivel escolher uma amostra representativa com o rigor estatistico necessário, assim como também seguir um mesmo paciente através de todos os seus contatos pelo centro de saúde; $o s$ dados se referem aos clientes que passavam por consulta, em cada clínica, naquele dia, pela primeira vez. A razão desta escolha baseou-se na suposição de que os clientes, numa primeira consulta, recebessem orientação mais ampla e maior número de dados fossem levantados. A amostra ficou constituida por 25 novos pacientes, sendo que, como os pacientes são examinados de acordo com a hora de chegada, tivemos oportunidade de observar a orientação recebida pelos clientes antigos também.

Os serviços observados foram os seguintes: Fichário, Matricula, Saúde da Criança, Clinica Dentária, Saúde do Adulto, Otorrinolaringologia e Oftalmologia, Dermatologia Sanitária e Visitas Domiciliares.

Um total de 25 novos pacientes foram observados durante o periodo de duas semanas de duração do estudo. 
CASTEllanos, R. A. - Orientação sobre saúde bucal em um Centro de Saúde. Rev. Saúde públ., S. Paulo, $11: 248-57,1977$.

\subsection{Técnica:}

Como estagiário para analisar o funcionamento intimo dos serviços do centro de saúde, utilizou-se a técnica da observação participante sem alertar o pessoal de saúde quanto ao desenvolvimento do presente estudo.

\subsection{Ficha:}

Elaborou-se uma ficha contendo os diversos aspectos a serem abordados com os pacientes. As fichas já preenchidas serviram de base para a elaboração do programa de educação em saúde bucal.

\section{RESULT A D O S}

O diagnóstico educativo elaborado a partir dos resultados da observação feita nos diferentes serviços permitiu-nos concluir que a orientação em saúde da boca recebida pelos clientes do Centro de Saúde é limitada e não sistemática. Apenas em alguns serviços foi mencionada, de forma não rotineira, a existência do serviço dentário, necessidade de marcar consulta com o dentista ou de aplicações tópicas de flúor.

\section{D I S C U S S Ã O}

Analisando os diversos serviços que funcionam no centro de saúde, verificou-se que em alguns seria mais dificil incluir educação em saúde da boca, ao passo que outros, pelo contrário, seriam os mais indicados para desenvolver um programa que visasse uma adequada orientação ao cliente e tentasse modificar, quando necessário, suas crenças, atitudes e comportamento em relação à saude bucal.

Entendemos por uma adequada orientação a informação sobre o funcionamento do serviço dental, e sobre as diversas medidas, tanto preventivas como curativas, que visam a promoção da saúde bucal e por modificaf̧ão de crenças, atitudes e comportamento a adoção de medidas preventivas e curativas, para prevenir ou resolver problemas de saúde da boca.

\subsection{Tratamento Educativo}

Elaborou-se um programa educativo a ser desenvolvido pelos diferentes serviços do Centro de Saúde, de forma incidental e integrado às suas atividades de acordo com as suas próprias possibilidades, e pela Clínica Dentária, de forma planejada para todo o decorrer do ano.

\subsubsection{Matrícula}

É neste Setor onde o cliente entra pela primeira vez num contato mais prolongado com o centro de saúde, e onde pode ser informado sobre:

- finalidade do centro - proporcionar medidas preventivas e curativas com participação ativa da população, para levar o individiuo ou comunidade a ter saúde geral, englobando como uma parte desta, a saúde bucal;

\section{- funcionamento da clinica dentária;}

- solução de flúor para adicionar à água de beber. Para haver um controle desta orientação bastaria que a clínica dentária mantivesse um registro das pessoas que solicitam a solução e sua periodicidade.

A finalidade destas informações é iniciar um processo educativo que deverá ir aumentando progressivamente e de modo repetitivo através dos diferentes serviços que o cliente utilize, devendo usar-se sempre como ponto de apoio para o início do processo educativo o motivo que leva o indivíduo a matricular-se no centro de saúde, posto que geralmente as pessoas procuram um serviço desta natureza para obter tratamento $\mathrm{e}$ remédios quando adoecem. $O$ conceito de prevenção, sobretudo nas classes menos favorecidas, ainda não forma parte do seu sistema de valores, sendo, portanto, esta a ocasião em que se deve enfatizar as finalidades do Centro. 
CASTELlayos, R. A. - Orientação sobre saúde bucal em um Centro de Saúde. Rev. Saúde pübl., S. Paulo, $11: 248-57,1977$.

\subsubsection{Saúde da criança}

A este serviço cabe um papel estratégico no desenvolvimento incidental do programa educativo, Consultando suas normas encontramos que deve desenvolver um programa de orientação sobre higiene da criança, no qual está incluída: "alimentação, hábitos alimentares corretos, controle médico-dentário, periodicidade da consulta médicodentista, profilaxia das doenças transmissiveis, cárie dental e prevenção de defeitos físicos".

O seguimento destas normas permitiria a integração dos conhecimentos sobre saúde da boca com as restantes recomendações que são dadas aos clientes depois da consulta médica, como na orientação sobre:

a) a utilidade dos alimentos para um desenvolvimento físico (peso e altura) adequado, incluir os que favorecem os dentes e a gengiva, principalmente os que exigem muita mastigação e não favorecem a formação de ácidos (carnes, frutas frescas, verduras (cruas) ${ }^{1,3}$;

b) a ingestão de vitaminas contidas nos alimentos ou sintéticas, especialmente dos tipos A, B, C e D, relacionando sua importância com a saúde bucal ${ }^{1,3}$;

c) a substituição de alimentos pouco nutritivos por outros de maior valor, falando, por analogia, sobre alimentos açucarados (balas, doces) que afetam a saúde bucal e sua substituição, sempre que possivel por outro tipo de alimentos (frutas, leite) ${ }^{1,3}$;

d) as vacinas, para proteção da criança contra o risco de doenças transmissiveis comuns na infância, relacionando a proteção que oferece o flúor aos dentes contra a cárie dental;

e) a idade em que as crianças devem tomar as diferentes vacinas, explicando que desde o nascimento a criança pode beber água contendo flúor na proporção de $1 \mathrm{ppm}$ por dia e que com a idade de 3 anos pode receber sua $1^{\text {a }}$ aplicação tópica de flủor ( $\mathrm{FNa}$ a $2 \%$ ) ou que, em casa, pode realizar bochechos com soluções de flúor diariamente ou semanalmente conforme a concentração ( $\mathrm{FNa}$ a $0,05 \%$ ou $0,2 \%$, respectivamente);

f) a escovação dos dentes (porque, como e quando) e limpeza (profilaxia) que o dentista executa para eliminar cálculo que afeta dentes e gengiva, quando das recomendaçōes sobre asseio, que incluem tomar banho, lavar as mãos antes de comer e limpeza das unhas;

g) a necessidade das visitas ao dentista para avaliação do estado de saúde bucal quando for enfatizada a importância da visita periódica ao médico para avaliação da saúde e do desenvolvimento da criança.

Recomendamos o uso de uma ficha de controle com o relatório do resumo das orientações fornecidas em cada consulta a fim de que haja redução ou aprofundamento de pontos não abordados ou ligeiramente abordados.

\subsubsection{Saúde materna}

De acordo com as normas do serviço, existe um programa de exercícios e palestras para grupos de gestantes - duas vezes por semana, após a consulta. Este ofereceria uma magnifica oportunidade para desenvolver uma série de atividades sobre saúde bucal (na época do estudo este programa não estava funcionando, pois encontrava-se em fase de reorganização). Outra atividade prevista, é a visita domiciliar, post-partum, cuja finalidade é orientar e ajudar a mãe nos cuidados ao bebê e a ela mesma. Esta é outra oportunidade para reforçar e avaliar as orientações recebidas durante o periodo de gestação. Da mesma forma como foi mencionada para a seção da Saúde da Criança, poderiam ser integrados os conhecimentos visados pelo programa através das recomendações que a 
Castellanos, R. A. - Orientação sobre saúde hucal em um Centro de Saúde. Rev. Saúde pübl., S. Paulo, 11:248-57, 1977.

gestante recebe no transcurso de sua gestação: (a) alimentação, (b) vitaminas, (c) dieta, (d) medidas preventivas, (e) asseio pessoal e (f) visitas periódicas.

\section{1.+ Clinica dental}

Esta seçāo deve ser a encarregada de completar e reforçar a orientação que as pessoas deverão ter recebido durante suas visitas ao Centro de Saúde e de motivá-las a adotar as práticas de higiene bucal condizentes com a saúde da boca. Esta motivação pode ser conseguida, em parte, com a apresentação de modelos, fotografias, diapositivos ou filmes que mostrem as conseqüências da não-adoção de medidas preventivas e do não-seguimento de determinado tipo de tratamento ou de recomendações dadas, consequiências estas que se traduzem no detrimento da saúde bucal, bem como mostrando o lado positivo da questão, ou seja, situações decorrentes da observância das normas condizentes a essa saúde; e, por outra parte, ganhando a confiança do paciente, através do contato mais prolongado na relação paciente-dentista-pessoal auxiliar.

\subsection{Pessoal para o Trabalho Educativo}

\section{Pessoal da Clinica Dental}

Sobre o dentista recai a responsabilidade de educar seus pacientes, assim como o de zelar para que os demais membros da equipe aproveitem ao máximo as oportunidades que se apresentem para levar a cabo esse trabalho educativo ${ }^{6}$.

Tem-se discutido quanto tempo deve ser devotado a esse tipo de atividade e a opinião tem sido que este não deve ocupar um percentual alto do tempo total, em detrimento das atividades de tratamento dental; assim sendo, o dentista deve delegar funções ao pessoal auxiliar. A auxiliar de consultório e a funcionária que faz as aplicações tópicas de flúor, em nosso caso, seriam as pessoas que estão ocupando um lugar chave e que deveriam ser treinadas para desen- volver o programa de saúde bucal proposto, utilizando para tal fim os periodos de espera entre consultas, durante as aplicações tópicas de flúor, antes e depois do tratamento curativo, enfim aproveitando todas as ocasiōes que se apresentarem. Elas se encarregariam de fazer as demonstrações de escovação dos dentes, de favorecer a solicitação e utilização da solução de flúor por parte dos pacientes, de motivar a continuidade do tratamento e das visitas periódicas e de contribuir para a modificação de hábitos. É imprescindivel que o dentista participe ativamente desse trabalho, contribuindo para tornar mais agradável - ambiente, ganhando a confiança das crianças e famíliares e aproveitando sistematicamente as ocasiones que se lhe apresentarem durante o tratamento odontológico para abordar temas condizentes à prevenção de novos problemas ou do tratamento em si ${ }^{\circ}$.

\section{Pessoal de Outros Serviços}

Os médicos, enfermeiros, educadoras sanitárias e auxiliares de enfermagem deverão também contribuir para o trabalho educativo, aproveitando as ocasiões oportunas e encaminhando os clientes à clínica dentária. Para isto, entretanto, devem conhecer 0 assunto e estar convencidos dos beneficios do programa de educação em saúde bucal.

\subsection{Material Audiovisual}

A falta de material audiovisual sobre aspectos de saúde da boca, é um fator negativo, pois este não só orientaria os clientes que sabem ler, como também a pessoa que orienta o cliente.

Os serviços mais adequados para sua fixação ou distribuição seriam Saúde da Criança, Saúde Materna e Clínica Dental.

\section{A $\mathrm{VALIAC} \AA \mathrm{O}$}

Para avaliar os resultados desse trabalho educativo, poderão ser utilizados os seguintes dados: 
CASTEllanos, R. A. - Orientação sobre saúde bucal em um Centro de Saúde. Rer. Saúde públ., S. Paulo, 11:248-57, 1977 .

\section{avaliação indireta:}

diminuição das faltas às consultas marcadas;

aumento na distribuição da solução de flúor;

aumento de novas consultas e, aumento de visitas periódicas para controle.

\section{avaliaşāo direta:}

técnica correta ou incorreta da escovação dos dentes;

efetividade da escovação com o auxilio de substancias reveladoras;

perguntas feitas pelo paciente e, indices de higiene bucal, antes e depois de introduzida a atividade que se deseja adotar.

Esses seriam, em nosso entender, os serviços sobre os quais recai a maior responsabilidade do programa educativo.

Deve-se salientar que os problemas de saúde bucal não se resolvem somente através do planejamento de programas de educação do público, mas, que a conscientização, o interesse e o conhecimento por parte do pessoal de saúde, são necessários para haver motivação e conseqüente observância das medidas que beneficiam a saúde individual, do grupo ou da comunidade.

Achamos que se os programas de educação em saúde da boca não têm rendido tanto quanto deles se esperava é por não se ter considerado as múltiplas variáveis bio-psico-sociais e culturais que influem reciprocamente e por não se dispor especificamente de informações completas acerca dos indivíduos, de seu meio familiar, de seus valores sociais e culturais, de suas crenças, atitudes, comportamento e aspirações ${ }^{4}$. Também deve-se levantar a questão se, nós, profissionais em saúde, estamos convecidos no intimo da necessidade de educar e educar-nos. Afinal, também pertencemos a esse grupo cultural que nos nutriu com suas crenças, atitudes e comportamento durante uma boa parte de nossa vida e da qual nos diferenciamos como sub-grupo apenas numa pequena etapa de nossa formação em ciências da saúde com planos incompletos até alguns anos atrás, apenas visando o tratamento curativo da doença. Então é válido perguntar:

Quantos de nós, profissionais de caúde, visitamos periodicamente o dentista?

Quantos de nós escovamos corretamente os dentes?

Quantos de nós nos privamos de uma sobremesa açucarada ou a substituimos por frutas?

Quantos de nós utilizamos o flúor para proteção dos dentes de nossos filhos, ou familiares?

Então o problema é devido à falta de educação dental? À falta de meios econômicos? Ao temor ao dentista?

Resta concluir nossa discussão, ressaltando a importância do Centro de Saúde como local de desenvolvimento de programas integrados, preventivos, curativos $e$ educativos.

\section{CONCLUSOES}

As observações feitas nos permitem concluir, com as limitaçōes já apontadas, que:

1. durante o periodo de observação não foi constatada, em alguns serviços, referência à saúde da boca;

2. as normas dos serviços não estão sendo observadas de forma adequada no que diz respeito à orientação em saúde da boca;

3. há falta de material audiovisual sobre aspectos de saúde da boca;

4. as medidas de prevenção de que dispõe o Centro em matéria dental não estão sendo utilizadas maciçamente pelo público.

\section{RECOMENDAC OE S}

1. Desenvolvimento de um programa educativo sobre aspectos de saúde da boca, incidental e planejado, integrado às atividades dos diferentes serviços, junto a clientes do Centro de Saúde (programa anexo) 
CASTELlaNOS, R. A. - Orientação sobre saúde bucal em um Centro de Saúde. Rev. Saúde públ., S. Paulo, $11: 248-57,1977$.

2. Utilização do pessoal existente no Centro para seu desenvolvimento, especialmente do pessoal responsável pela seção) de higiene dentária.

3. Treinamento do pessoal, pelo dentista, sobre os conceitos e técnicas a serem desenvolvidas pelo programa.

4. Revisão e atualização das normas em relação à educação em saúde da boca.

5. Utilização de cartazes e folhetos, elaborados com a técnica correta para obter a máxima utilidade.

\section{A G R A D E I M EN TOS}

A Dra. Erna M. Bastian, nessa época Chefe da Seção de Enfermagem do Centro de Saúde Geraldo de Paula Souza da Faculdade de Saúde Pública da USP (cujo Diretor foi o saudoso Dr. Oswaldo Cruz $\dagger$ ), por terem permitido realizar o presente estudo, à Enfermeira Alice Derntl bem como aos demais funcionários do Centro de Saúde por facilitar a realização do mesmo e, à Dra. Ruth Sandoval Marcondes pela orientação recebida.

RSPU-B/356

Castellanos, R. A. [Dental health education in a public health centre.]

Rev. Saúde públ., S. Paulo, $11: 248-57,1977$.

ABSTRACT: This paper deals with a study made with the purpose of observing dental health, education of patients coming for the first time to a Health Center. The study was carried out during two weeks and 25 patients were observed through "Participant Observation". Data for the "Educational Diagnosis" was collected in a card specially designed for it. Results showed that dental health orientation was not given by the staff to patients. An educational programme about dental health is suggested to be integrated with the activities of the various services, being the Dentist responsible for the staff programme coordination and evaluation. Finally the importance of the health center for the development of preventive, curative and educational integrated programmes is emphasized. vices.

UNITERMS: Oral health. Health education, dental. Community health ser-

\section{REFERENCIAS BIBLIOGRAFICAS}

1. FLORIDA, State Department of Education. A guide design for teaching dental health in Florida schools. Tallahasse. Fla., 1963 (Bulletin, 7).

2. GROUTH, R. E. Health teaching in schools. 3rd ed, Philadelphia, Saunders, 1958.

3. LIPATOVA $\mathrm{S}$. L. Health education as a means to prevent dental caries in children. Int. J. Hith, Educ, 8:135-40, 1964.

4. ORGANIZACION MUNDIAL DE LA SALUD. Comitê de Expertos de la OMS en Educación Sanitária e Higiene Dental, Ginebra, 1969. Eaucación Sanitária e Higiene Dental. Ginebra, 1970. (OMS - Ser. inf. tecn., 449).
5. ORGANIZACION MUNDIAL DE LA SALUD. Comitè de Expertos de la OMS en Higiene Dental, Ginebra. 1964. Organizaça de serviços de higiene dental, Ginebra, 1965. (OMS Ser. inf. tecn., 298)

6. SUNDRAM, S. C. Educational approach to dental health: problems and promotion in Malaysia. Int. $J$. Hlth. Educ., 12:184-91, 1969.

7. YoUNG, M. A. C. Dental health education: an overview of selected concepts and principles relevant to programme planning. Int. J. Hith. Educ., $13: 1-26$. 1970

Recebido para publicaçāo em 0.3/12/1976 Aprovado para publicação em 17/12/1976 
CASTEllanos, R. A. - Orientação sobre saúde bucal em um Centro de Saúde. Rev. Saúde públ., S. Paulo, 11:248-57, 1977.

ANEXO

\section{PROGRAMA DE ORIENTAÇAO SOBRE SAÚDE DA BOCA EM UM CENTRO DE SAÚDE}

\section{OBJETIVO GERAL:}

Proporcionar subsídios, ao indivíduo, família e comunidade, para a obtenção, conservação e restauração da saúde bucal.

\subsection{Objetivos especificos}

1.1.1 conseguir que o paciente aprenda a escovar corretamente seus dentes;

1.1 .2 conseguir que o paciente consulte periodicamente o dentista (1 vez por ano).

1.1.3 proporcionar conhecimentos sobre estrutura dental;

1.1.4 levar o paciente a adotar medidas preventivas que o ajudem na redução de determinadas doenças da boca;

1.1.5 modificar certos hábitos alimentares que trazem prejuizos à saúde da boca.

\subsection{Conceito de satide da boca}

"Estado de normalidade funcional dos dentes e periodonto, assim como partes vizinhas da cavidade bucal e das diversas estruturas relacionadas com a mastigação e que formam parte do complexo máxilo-facial." (Comitê de peritos da OMS).

1.2.1 Conceito Operacional: através do processo educativo, conseguir que o indivíduo: conserve seus dentes limpos através da escovação correta; não apresente alterações de cor, textura ou consistência da gengiva; apresente-se livre de cárie dental (por restauração ou por ausência do processo carioso); adote medidas preventivas e procure modificar seus hábitos, alimentares ou de outro tipo, que afetem sua saúde bucal.

\section{METODOLOGIA}

2.1 Forma indireta: através de cartazes e folhetos, elaborados de acordo com as técnicas adequadas para obter a máxima utilidade, que estimulem a adoção de medidas preventivas e a utilização da clínica dentária para controle bucal periódico.

2.2 Forma direta: de forma incidental e de forma programada.

2.2.1 Pessoal responsável: os responsáveis pela orientação dos pacientes, especialmente enfermeiros, educadores em saúde, pessoal auxiliar e médicos, participariam do programa educativo, nas suas duas formas diretas: a incidental e a programada.

O dentista seria o responsável pelo treinamento do pessoal, especialmente das auxiliares que colaboram com a clínica dentária e participam da educação direta ao público.

2.3 Desenvolvimento do programa: este seria dividido em 8 ou 4 etapas:

- semanalmente, em dia e horário previamente estabelecidos, se dedicaria cerca de meia hora para a exposição de cada tópico do programa, de modo a completá-lo em dois meses; ou 1 hora por semana, de modo a completá-lo num mês.

- Bimensal ou mensalmente haveria repetição do mesmo programa.

O conteúdo programático deverá adequar-se, tanto em extensão como em profundidade, ao grupo etário (crianças ou adultos) e aos seus interesses e conhecimentos.

Como meio de comunicação com os usuários do Centro seriam colocados cartazes indicando o dia, hora e etapa 
CASTEllanos, R. A. - Orientação sobre saúde bucal em um Centro de Saúde. Rev. Saúde públ., S. Paulo, 11:248-57, 1977.

do programa a ser abordada em cada semana, visando o comparecimento às palestras de acordo com as conveniências de cada um dos clientes.

Essa parte formal do programa seria da responsabilidade da clínica dentária, que deverá contar, para isso, com o material e recursos audiovisuais adequados.

\section{CONTEÚDO DO PROGRAMA}

\subsection{Funcionamento da Clínica Dental} grupo etário que é atendido; tipo de serviço oferecido; instruções de como marcar consulta.

\subsection{Escovação dos dentes}

\subsubsection{Objetivo da escovação}

evitar a formação da placa bacteriana;

eliminar os resíduos alimentares;

estimular a gengiva e prevenir sua alteração;

melhorar a estética.

\subsubsection{Freqüência da escovação} após as refeições;

após a ingestão de alimentos açucarados.

3.2.3 Técnica da escovação

procedimento;

demonstração e repetição (utilizando modelo e escova)

\subsubsection{Uso de fio dental}

vantagens;

precauções.

3.2.5 Uso de substâncias evidenciadoras de restos de alimentos e de placa bacteriana.

\subsubsection{Avaliação}

utilizando um modelo e uma escova - paciente deverá ser capaz de repetir a técnica e o procedimento aprendido;

usando a técnica aprendida, o cliente escovará seus dentes no consultório dental e pelo menos $90 \%$ das superficies dentárias deverão estar livres de resíduos; utilizando a substância evidencia- dora, o cliente deverá ser capaz de indicar, com a ajuda de um espelho, os locais onde os resíduos alimentares não foram removidos pela escovação de seus dentes;

usando o fio dental, o paciente deverá ser capaz de mostrar a forma correta de passá-lo entre os dentes; pelo menos $90 \%$ das papilas dentárias não deverão sangrar.

\subsection{Estrutura dental}

\subsubsection{Dentição temporária e permanente} número e forma dos dentes temporários;

número e forma dos dentes permanentes.

3.3.2 Tecidos de constituifão do dente esmalte;

cemento;

dentina;

polpa dentária.

\subsubsection{Função dos dentes} mastigação dos alimentos; fonação; estética.

3.3.4 Importância do primeiro molar permanente

idade da erupção;

perigos ao confundi-lo como dente decíduo.

3.3.5 Conceito de periodonto.

\subsubsection{Avaliação}

mostrando ao paciente um modelo de dentes permanentes e outro de dentes temporários, este deverá ser capaz de diferenciá-los;

dando ao paciente um molar deciduo e um molar permanente ele deverá diferenciá-los;

o cliente deverá ser capaz de desenhar um dente e dar o nome dos 4 tecidos que o constituem.

\subsection{Cárie dental}

\subsubsection{Conceito}

desenvolvimento do processo carioso; conseqüuências. 
CASTEllanOS, R. A. - Orientação sobre saúde bucal em um Centro de Saúde, Rev. Saúde públ. S. Paulo, 11:248-57, 1977.

\subsubsection{Aspectos preventivos} alimentação e dieta; hábitos higiênicos; utilização do flúor.

\subsubsection{Aspectos curativos} restaurações (amálgama, silicato e outras); extrações.

\subsubsection{Avaliação}

ao término desta unidade, o paciente deverá ser capaz de: descrever como se inicia e progride o processo carioso; solicitar periodicamente a solução de flúor para adicionar à água de beber;

solicitar atendimento odontológico para os dentes afetados pela cárie.

\subsection{Doença periodontal}

\section{5 .1 Conceito}

desenvolvimento do processo destrutivo;

consequências.

\subsubsection{Aspectos preventivos}

escovação e massagem da gengiva; consumo de alimentos duros e detergentes;

prevenção da formação da placa bacteriana;

limpezas (profilaxias) periódicas para eliminar o tártaro.

\subsubsection{Aspectos curativos}

retração da gengiva; eliminação de bolsas.

\subsubsection{Avaliação}

O paciente deverá ser capaz de: descrever como é e onde se localiza a papila interdental;

observar ao microscópio os movimentos dos microrganismos presentes na placa bacteriana;

descrever o início e o progresso da doença periodontal.

\subsection{Má oclusão}

\subsubsection{Causas principais}

uso da chupeta;

(hupar lábio ou dedo; retenção ou perda precoce de dentes decíduos:

deficiências vitamínicas.

\subsubsection{Avaliação}

através de informação, obtida dos pacientes, sobre mudanças de hábitos (abandono de chupeta, ou de chupar o dedo, etc.).

3.7 Importância da visita periódica ao dentista

controle sobre estado dos dentes e tecidos adjacentes;

redução da cárie dental nas suas dimensões qualitativas e quantitativas; prevenção de alterações periodontais por meio de profilaxias.

3.7.1 Avaliação

O paciente deverá relatar a importância da visita periódica ao dentista, dando pelo menos 3 razóes como justificativa;

respeito ao cumprimento das consultas marcadas, sem apresentar mais de uma falta, durante o tratamento; retorno periódico para marcação de consulta, conforme as recomendações recebidas pelo dentista.

\subsection{Importância da dieta}

ingestão de alimentos ricos em cálcio e vitaminas $\mathrm{A}, \mathrm{B}, \mathrm{C}$ e $\mathrm{D}$;

ingestão de açúcares (tipo e freqüência).

3.8.1 Avaliação

Indiretamente, através da descrição da dieta consumida pelo paciente.

3.9 Interrelação da saúde bucal com a saúde geral

infecçōes secundárias a outros órgãos; transtornos gástricos;

diminuição da capacidade física do indivíduo;

problemas psicológicos.

Avaliação

indiretamente, através da procura do paciente da clinica dentária para consultar ou resolver problemas de saude da boca, com o objetivo de prevenir problemas que interfiram em sua saúde geral. 